\title{
The Septoria blight on the spring wheat varieties in the Western Siberia
}

\author{
Toropova E.Yu. ${ }^{1 *}$, Kazakova O.A. ${ }^{1,2}$, Piskarev V.V. ${ }^{3}$ \\ ${ }^{1}$ Novosibirsk State Agrarian University, Novosibirsk, Russia \\ ${ }^{2}$ All-Russian Research Institute of Phytopathology, Moscow region, Russia \\ ${ }^{3}$ Institute of Cytology and Genetics, SB RAS, Novosibirsk, Russia \\ *e-mail:79139148962@yandex.ru
}

The aim of the work was to clarify the Septoria causative agents species composition on leaves and spike and to evaluate the spring wheat varieties effectiveness in the disease controlling in the Western Siberia forest-steppe zone. Studies were carried out in 20162018 according to generally accepted methods. Spring wheat leaves and ears Septoria blight is widespread in Western Siberia, causing a decrease in yield by up to $50 \%$ or more with the deterioration in the grain quality. The Septoria blight causative agents' specific composition is represented by Parastagonospora nodorum, Septoria tritici and $S$. avenae f. sp. tritici, and the species ratio varied by region, variety and within plant organs: in the Novosibirsk region the strongest $P$. nodorum domination was revealed, in the Tyumen region $P$. nodorum dominance was not absolute and was disturbed in some geographical points by $S$. tritici and $S$. avenae f. sp. tritici. In the Altai Territory, the $P$. nodorum dominance was revealed at all points, but it was less significant compared to the Novosibirsk Region and was accompanied by the widespread occurrence of S. tritici. The immunological assessment of spring wheat 23 varieties collection from different origin did not allow identification of samples immune to Septoria. A differentiated manifestation of resistance signs to leaves and ear Septoria disease has been established. The complex revealed resistance some varieties (Orenburg 23, Vyatchanka, also Long Chun 7 Hao from China) have shown, they combined reduced susceptibility to Septoria disease of the leaves and ear. The varieties collections study from three regions of Siberia in the epiphytotic year made it possible to identify the following trend: compared with the Omsk and Kurgan regions, the Septoria blotch causative agent transmission was most active with seeds of the Novosibirsk breeding varieties. 